\title{
Robot-assisted Therapy in Stroke Rehabilitation
}

\author{
Won Hyuk Chang, ${ }^{a}$ Yun-Hee Kim ${ }^{\mathrm{a}, \mathrm{b}}$ \\ ${ }^{a}$ Department of Physical and Rehabilitation Medicine, Stroke and Cerebrovascular Center, Samsung Medical Center, Sungkyunkwan University School of \\ Medicine; 'Samsung Advanced Institute for Health Science and Technology, Sungkyunkwan University, Seoul, Korea
}

Research into rehabilitation robotics has grown rapidly and the number of therapeutic rehabilitation robots has expanded dramatically during the last two decades. Robotic rehabilitation therapy can deliver high-dosage and high-intensity training, making it useful for patients with motor disorders caused by stroke or spinal cord disease. Robotic devices used for motor rehabilitation include end-effector and exoskeleton types; herein, we review the clinical use of both types. One application of robot-assisted therapy is improvement of gait function in patients with stroke. Both end-effector and the exoskeleton devices have proven to be effective complements to conventional physiotherapy in patients with subacute stroke, but there is no clear evidence that robotic gait training is superior to conventional physiotherapy in patients with chronic stroke or when delivered alone. In another application, upper limb motor function training in patients recovering from stroke, robot-assisted therapy was comparable or superior to conventional therapy in patients with subacute stroke. With end-effector devices, the intensity of therapy was the most important determinant of upper limb motor recovery. However, there is insufficient evidence for the use of exoskeleton devices for upper limb motor function in patients with stroke. For rehabilitation of hand motor function, either end-effector and exoskeleton devices showed similar or additive effects relative to conventional therapy in patients with chronic stroke. The present evidence supports the use of robot-assisted therapy for improving motor function in stroke patients as an additional therapeutic intervention in combination with the conventional rehabilitation therapies. Nevertheless, there will be substantial opportunities for technical development in near future.

Keywords Stroke; Robot-assisted therapy; Motor disorder; Rehabilitation

\author{
Correspondence: Yun-Hee Kim \\ Department of Physical and \\ Rehabilitation Medicine, Division for \\ Neurorehabilitation, Stroke and \\ Cerebrovascular Center, Samsung \\ Medical Center, Samsung Advanced \\ Institute for Health Science and \\ Technology, Sungkyunkwan University \\ School of Medicine, 81 Irwon-ro, \\ Gangnam-gu, Seoul 135-710, Korea \\ Tel: +82-2-3410-2824, 2818 \\ Fax: +82-2-3410-0388 \\ Email: yunkim@skku.edu
}

Received: June 18, 2013 Revised: July 30, 2013 Accepted: August 1, 2013

This article was supported by a KOSEF grant (M10644000022-06N4400-02210) funded by the Korean government.

The authors have no financial conflicts of interest.

\section{Introduction}

Stroke is a common, serious, and disabling health-care problem throughout the world. ${ }^{1}$ In particular, in Korea, which is very rapidly changing into an "Aging Society," the incidence of stroke has increased, albeit gradually, during the last few decades. ${ }^{2}$ On the other hand, the mortality rate from stroke has declined over time, ${ }^{2}$ resulting in an increased prevalence of stroke in Korea.
Unfortunately, one third of stroke survivors achieve only a poor functional outcome five years after the onset of stroke. ${ }^{3}$ Therefore, stroke-related problems are a serious burden to both patients and their families. ${ }^{4}$ Although great advances have been made in acute stroke management, the majority of post-stroke care to reduce patients' dependency relies on rehabilitation treatments.

Neuroplasticity is the basic mechanism underlying improve- 
ment in functional outcome after stroke. ${ }^{5}$ Therefore, one important goal of rehabilitation of stroke patients is the effective use of neuroplasticity for functional recovery. Other principles of stroke rehabilitation are goal setting, high-intensity practice, multidisciplinary team care, and task-specific training. ${ }^{1}$ Therefore, high-dose intensive training ${ }^{6}$ and repetitive practice of specific functional tasks ${ }^{7}$ are important for recovery after stroke. These requirements make stroke rehabilitation a labor-intensive process.

Robotic technology has developed remarkably in recent years, with faster and more powerful computers and new computational approaches as well as greater sophistication of electro-mechanical components. ${ }^{8}$ This advancement in technology has made robotics available for rehabilitation intervention. A robot is defined as a re-programmable, multi-functional manipulator designed to move material, parts, or specialized devices through variable programmed motions to accomplish a task. ${ }^{9}$ The most important advantage of using robot technology in rehabilitation intervention is the ability to deliver high-dosage and high-intensity training. ${ }^{10}$ This property makes robotic therapy a promising novel technology for rehabilitation of patients with motor disorders caused by stroke or spinal cord disease. Research into rehabilitation robotics has been growing rapidly, and the number of therapeutic rehabilitation robots has increased dramatically during the last two decades. ${ }^{11}$

Rehabilitation robots can be divided into therapeutic and assistive robots. The purpose of assistive robots is compensation, whereas therapeutic robots provide task-specific training. ${ }^{12}$ In this manuscript, the authors will focus on the usefulness of therapeutic robots in patients with stroke. The types of robotic devices used for motor training are end-effector-type devices and exoskeleton-type devices (Figure 1). ${ }^{13}$ End-effector devices work by applying mechanical forces to the distal segments of limbs. End-effector type robots offer the advantage of easy setup but suffer from limited control of the proximal joints of the limb, which could result in abnormal movement patterns. In contrast, exoskeleton-type robotic devices have robot axes aligned with the anatomical axes of the wearer. These robots provide direct control of individual joints, which can minimize abnormal posture or movement. Their construction is more complex and more expensive than that of the end-effector type. In this manuscript, the authors will summarize the recent research concerning both the end-effector and exoskeleton types of robot devices. We will also discuss the current status of robotassisted therapy in stroke rehabilitation.

\section{Robot-assisted therapy for gait function}

\section{End-effector-type robotic devices}

Seven randomized controlled trials that compared robot-assisted therapy that uses end-effector-type devices with conventional therapies for improving gait function after stroke were selected for review (Table 1)..$^{14-20}$

Two studies conducted in patients with chronic stroke reported comparable effects on gait function between the robotassisted therapy and conventional gait training. ${ }^{14,17}$ These results indicate that the robot-assisted therapy with end-effector-type devices cannot replace conventional therapy in patients with chronic stroke. However, the other five trials, which enrolled patients with subacute stroke, demonstrated that robot-assisted therapy in combination with conventional physiotherapy produced greater improvement in gait function than conventional
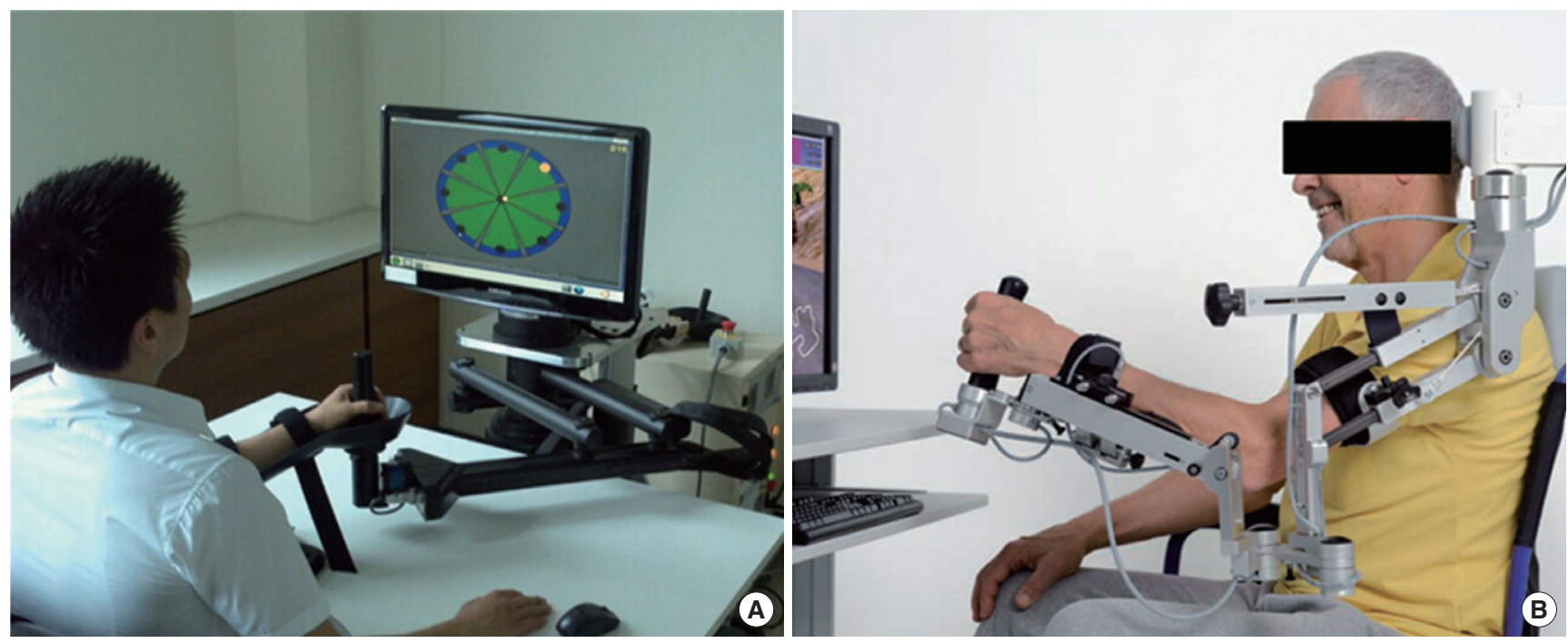

Figure 1. Examples of robotic devices for motor training (A) End-effector type (InMotion 2.0 Interactive Motion Technologies, Watertown, MA, USA), (B) Exoskeleton type (Armeo ${ }^{\circledR}$, Hocoma, Switzerland). 
Table 1. Robot-assisted therapy for gait function

\begin{tabular}{|c|c|c|c|c|c|c|}
\hline Authors & $\begin{array}{l}\text { Robotic } \\
\text { device }\end{array}$ & $\begin{array}{l}\text { Number of } \\
\text { participants }\end{array}$ & $\begin{array}{l}\text { Stroke } \\
\text { stage }\end{array}$ & Intensity & $\begin{array}{l}\text { Concomitant } \\
\text { therapy }\end{array}$ & $\begin{array}{l}\text { Summary of results in comparison } \\
\text { with conventional therapies }\end{array}$ \\
\hline \multicolumn{7}{|l|}{ End-effector-type devices } \\
\hline Werner et al., 2002 & Gait trainer & 30 & Subacute & 20 minutes, 5 times per week for 4 weeks & No & No difference \\
\hline Peurala et al., 2005 & Gait trainer & 45 & Chronic & 20 minutes, 5 times per week for 3 weeks & No & No difference \\
\hline Tong et al., 2006 & Gait trainer & 54 & Subacute & 20 minutes, 5 times per week for 4 weeks & Yes & More effective \\
\hline Dias et al., 2007 & Gait trainer & 40 & Chronic & 40 minutes, 5 times per week for 4 weeks & No & No difference \\
\hline Pohl et al., 2007 & Gait trainer & 155 & Subacute & 20 minutes, 5 times per week for 4 weeks & No & More effective \\
\hline Peurala et al., 2009 & Gait trainer & 56 & Subacute & 20 minutes, 5 times per week for 3 weeks & Yes & More effective \\
\hline Morone et al., 2011 & Gait trainer & 48 & Subacute & 20 minutes, 5 times per week for 4 weeks & No & More effective \\
\hline \multicolumn{7}{|l|}{ Exoskeleton devices } \\
\hline Mayr et al., 2007 & Lokomat & 16 & Subacute & 30 minutes, 5 times per week for 4.5 weeks & No & More effective \\
\hline Husemann et al., 2007 & Lokomat & 32 & Subacute & 30 minutes, 5 times per week for 4 weeks & Yes & More effective \\
\hline Hornby et al., 2008 & Lokomat & 62 & Chronic & 30 minutes, 12 sessions total & No & Less effective \\
\hline Jung et al., 2008 & Lokomat & 25 & Chronic & 30 minutes, 3 times per week for 4 weeks & Yes & More effective \\
\hline Hidler et al., 2009 & Lokomat & 72 & Subacute & 1 hour, 12 sessions total & No & Less effective \\
\hline Westlake \& Patten, 2009 & Lokomat & 16 & Chronic & 30 minutes, 3 times per week for 4 weeks & Yes & More effective \\
\hline Schwartz et al., 2010 & Lokomat & 67 & Subacute & 30 minutes, 3 times per week for 6 weeks & Yes & More effective \\
\hline Chang et al., 2012 & Lokomat & 37 & Subacute & 40 minutes, 5 times per week for 2 weeks & Yes & No difference \\
\hline
\end{tabular}

gait training alone. ${ }^{15,16,18-20}$ This means that the addition of robot-assisted therapy with end-effector-type devices to conventional physiotherapy can be recommended for use in patients with subacute stroke.

\section{Exoskeleton-type robot devices}

Eight randomized controlled trials that investigated the use of robot-assisted therapy with exoskeleton devices for improvement of gait function in patients with stroke were selected for review (Table 1). ${ }^{21-28}$ Two studies from 2007 reported superior results from robot-assisted therapy with exoskeleton devices in comparison with conventional physiotherapy. ${ }^{24,26}$ Both trials recruited relatively small numbers of patients. The first was a pilot study in patients with subacute stroke. ${ }^{24}$ Then, in 2008, Hornby et al. ${ }^{23}$ performed a randomized controlled study comparing the effects of robot-assisted gait training that uses exoskeleton devices and manual facilitation that uses an assist-as-needed paradigm on gait function in patients with chronic stroke. Their results demonstrated that therapist-assisted training yields greater improvements in walking ability in ambulatory stroke survivors than does a similar dosage of robot-assisted training. Hidler et $\mathrm{al}^{22}$ also investigated the usefulness of robot-assisted therapy in patients with subacute stroke in a multicenter randomized trial. They concluded that the diversity of conventional gait training interventions appeared to be more effective than robot-assisted gait training for improving walking ability. Therefore, these two reports agreed that at similar training intensities, conventional therapy is more effective than robot-assisted therapy with exoskeleton devices for recovery of gait function after stroke. However, other reports documented similar or superior effects of ro- bot-assisted therapy in combination with conventional physiotherapy versus conventional therapy alone on gait recovery, especially in patients with subacute stroke. ${ }^{21,27}$ In 2009 , a study by Schwartz et al. ${ }^{49}$ with a larger number of participants concluded that locomotor therapy by using robot devices in combination with regular physiotherapy produced promising effects on gait function in patients with subacute stroke in comparison with regular physiotherapy alone. ${ }^{27}$ Therefore, robot-assisted therapy with exoskeleton devices may not be able to replace conventional physiotherapy for improving gait function in patients with stroke but rather is recommended for use in combination with conventional physiotherapy, preferably in the subacute stage of stroke. However, there is insufficient research on the additional effect of robot-assisted therapy on gait function in the chronic stage of stroke.

\section{Robot-assisted therapy for upper limb and hand motor function}

\section{End-effector-type robotic devices}

Fourteen randomized controlled trials comparing robot-assisted therapy that use end-effector-type devices with conventional therapies for improvement of upper limb motor function after stroke were selected for review (Table 2). ${ }^{29-41}$ The metaanalysis in a 2012 Cochrane review demonstrated that robotassisted arm training improved upper limb function (standardized mean difference $0.45 ; 95 \%$ confidence interval (CI), 0.20 to $0.69 ; P=0.0004) .{ }^{42}$ However, more detailed analysis is needed to develop guidelines for individual stroke rehabilitation. A study by Fasoli et al. ${ }^{32}$ comprising 56 patients with subacute 
Table 2. Robot-assisted therapy for upper limb motor function

\begin{tabular}{|c|c|c|c|c|c|c|c|}
\hline \multirow[t]{2}{*}{ Authors } & \multirow{2}{*}{ Robotic device } & \multirow{2}{*}{$\begin{array}{l}\text { Number of } \\
\text { participants }\end{array}$} & \multirow{2}{*}{$\begin{array}{l}\text { Stroke } \\
\text { stage }\end{array}$} & \multirow[t]{2}{*}{ Intensity } & \multirow{2}{*}{$\begin{array}{l}\text { Concomitant } \\
\text { therapy }\end{array}$} & \multicolumn{2}{|c|}{$\begin{array}{l}\text { Summary of results in comparison with } \\
\text { conventional therapies }\end{array}$} \\
\hline & & & & & & Upper limb function & Activities of daily living \\
\hline \multicolumn{8}{|c|}{ End-effector-type devices } \\
\hline Lum et al., 2002 & MIME & 27 & Chronic & 55 minutes, 24 sessions total over 8 weeks & No & No difference & Not assessed \\
\hline Fasoli et al., 2004 & MIT-MANUS & 56 & Subacute & 1 hour, 5 times per week for 5 weeks & No & More effective & More effective \\
\hline Hesse et al., 2005 & Bi-Manu-Track & 44 & Subacute & 30 minutes, 5 times per week for 6 weeks & Yes & More effective & No difference \\
\hline Daly et al., 2005 & InMotion & 12 & Chronic & $\begin{array}{l}5 \text { hours per day, } 5 \text { days per week for } \\
12 \text { weeks }\end{array}$ & Yes & No difference & Not assessed \\
\hline Lum et al., 2006 & MIME & 30 & Subacute & 1 hour, 15 sessions over 4 weeks & No & No difference & No difference \\
\hline Masiero et al., 2007 & NeReBot & 35 & Subacute & 4 hours per week for 5 weeks & Yes & No difference & More effective \\
\hline Volpe et al., 2008 & InMotion2 & 21 & Chronic & 1 hour, 3 times per week for 6 weeks & No & No difference & No difference \\
\hline Lo et al., 2010 & MIT-MANUS & 127 & Chronic & a maximum of 36 sessions over 12 weeks & No & More effective & Not assessed \\
\hline Burgar et al., 2011 & MIME & 54 & Subacute & 1 hour, 5 times per week for 3 weeks & No & No difference & No difference \\
\hline Conroy et al., 2011 & $\begin{array}{l}\text { InMotion } 2.0 \\
\text { Shoulder/Arm } \\
\text { Robot }\end{array}$ & 57 & Chronic & 1 hour, 3 sessions per week for 6 weeks & No & No difference & More effective \\
\hline Liao et al., 2011 & Bi-Manu-Track & 20 & Chronic & $\begin{array}{l}90 \text { to } 105 \text { minutes, } 5 \text { days per week for } \\
4 \text { weeks }\end{array}$ & Yes & No difference & More effective \\
\hline Masiero et al., 2011 & NeReBot & 21 & Chronic & $\begin{array}{l}\text { Twice a day for } 20 \text { minutes, } 5 \text { days per } \\
\text { week for } 5 \text { weeks }\end{array}$ & Yes & No difference & No difference \\
\hline Hsieh et al., 2012 & Bi-Manu-Track & 54 & Chronic & $\begin{array}{l}\text { High intensity: } 20 \text { sessions for } 90 \text { to } 105 \\
\text { minutes, } 5 \text { days per week for } 4 \text { weeks } \\
\text { Low intensity: same amount assessed, } \\
\text { but only half of the number of repetitions }\end{array}$ & Yes & $\begin{array}{l}\text { High: More effective } \\
\text { Low: No difference }\end{array}$ & No difference \\
\hline Wu et al., 2013 & Bi-Manu-Track & 42 & Chronic & $\begin{array}{l}90 \text { to } 105 \text { minutes, } 5 \text { days per week for } \\
4 \text { weeks }\end{array}$ & Yes & More effective & Not assessed \\
\hline \multicolumn{8}{|l|}{ Exoskeleton devices } \\
\hline Kahn et al., 2006 & ARM-Guide & 19 & Chronic & 45 minutes, 24 sessions over 8 weeks & No & No difference & Not assessed \\
\hline Fazekas et al., 2007 & REHA ROB & 15 & Chronic & $\begin{array}{l}30 \text { minutes, } 20 \text { consecutive work } \\
\text { days ( } 5 \text { weeks) }\end{array}$ & Yes & More effective & Less effective \\
\hline Mayr et al., 2008 & ARMOR & 8 & Chronic & 5 times per week for 6 weeks & No & No difference & Not assessed \\
\hline Houseman et al., 2009 & T-WREX & 28 & Chronic & $\begin{array}{l}30 \text { minutes, } 5 \text { times per week for } \\
8-9 \text { weeks }\end{array}$ & No & No difference & No difference \\
\hline
\end{tabular}

stroke reported that patients who received conventional therapy alone showed little improvement, whereas patients who received robotic training plus conventional therapy continued to improve in the latter half of the inpatient rehabilitation period. This means that robot-assisted therapy is effective for improving upper limb motor function in patients with subacute stroke. A study by Lo et al. ${ }^{36}$ that recruited 127 chronic stroke patients reported that robot-assisted therapy and conventional therapy produced similar amounts of improvement after 12 weeks of treatment. However, after 36 weeks of therapy, the robot-assisted therapy achieved greater motor improvement than did conventional therapy. A study in patients with chronic stroke by Hsief et al..$^{34}$ also found significantly greater improvement in upper limb motor function in the higher-intensity robot-assisted training group than in the control treatment group. In contrast, upper limb motor recovery did not differ significantly between the lower-intensity training group and the control group. These findings suggest that the intensity is the most important parameter of robot-assisted therapy for upper limb motor recovery in patients with chronic stroke.

Nine of the 14 randomized controlled trials that examined robot-assisted therapy with end-effector-type devices assessed the influence of robot-assisted training on activities of daily living $(\mathrm{ADL})$ in patients with stroke. ${ }^{29,30,32-35,38-41}$ These nine reports demonstrated that robot-assisted training yielded similar or better effects on $\mathrm{ADL}$ in comparison with conventional therapy. The 2012 Cochrane review meta-analysis demonstrated that robot-assisted arm training improved $\mathrm{ADL}$ performance (SMD, 0.43 ; 95\% CI, 0.11 to $0.75 ; P=0.009$ )..$^{42}$ In addition, studies in patients with subacute stroke suggested that patients who received additional robotic therapy showed greater improvements in $\mathrm{ADL} .{ }^{32,40}$ However, trials in patients with chronic stroke demonstrated no additional improvement in $\mathrm{ADL}$ over conventional therapy ${ }^{34}$ In summary, robot-assisted therapy for upper limb motor function provides an additional effect on ADL function only in patients with subacute stroke. Further 
Table 3. Robot-assisted therapy for hand motor function

\begin{tabular}{|c|c|c|c|c|c|c|}
\hline Authors & Robotic device & $\begin{array}{l}\text { Number of } \\
\text { participants }\end{array}$ & $\begin{array}{l}\text { Stroke } \\
\text { stage }\end{array}$ & Intensity & $\begin{array}{l}\text { Concomitant } \\
\text { therapy }\end{array}$ & $\begin{array}{l}\text { Summary of results in comparison } \\
\text { with conventional therapies }\end{array}$ \\
\hline \multicolumn{7}{|l|}{ End-effector-type devices } \\
\hline Fischer et al., 2007 & $\begin{array}{l}\text { Cable orthosis/ } \\
\text { Pneumatic orthosis }\end{array}$ & 15 & Chronic & 1 hour, 3 times per week for 6 weeks & No & No difference \\
\hline Connelly et al., 2010 & PneuGlove & 14 & Not described & 1 hour, 3 times per week for 6 weeks & No & No difference \\
\hline Hwang et al., 2012 & Amadeo & 17 & Chronic & 20 minutes, 20 sessions total over 4 weeks & No & More effective \\
\hline \multicolumn{7}{|l|}{ Exoskeleton devices } \\
\hline Takahashi et al., 2008 & HAWARD & 13 & Chronic & 1.5 hours, 5 times per week for 3 weeks & No & More effective \\
\hline Kutner et al., 2010 & Hand Mentor & 17 & Chronic & 60 hours over 3 weeks & Yes & No difference \\
\hline
\end{tabular}

studies may be needed to draw a definite conclusion about the effect of robot-assisted training on $\mathrm{ADL}$ in patients with chronic stroke.

Three randomized controlled trials concerning hand motor function in patients with stroke were selected for review (Table 3). ${ }^{43-45}$ All three studies showed similar or superior effects of robot-assisted training in comparison with conventional therapy on hand motor function in patients with stroke. Hwang et $\mathrm{al}^{45}$ demonstrated that robot-assisted therapy provided dose-dependent improvement in hand function. However, all three trials were single-center studies with relatively small numbers of participants, all in the chronic stage of stroke, and there was no randomized controlled trial that included subacute stroke patients as participants Furthermore, there was no assessment of $\mathrm{ADL}$ function after robot-assisted therapy for hand motor function. Therefore, these results suggest that robot-assisted therapy with end-effector devices may yield similar or greater improvement in hand motor function in patients with chronic stroke, but there is insufficient research to support an effect in patients with subacute stroke. Therefore, well-designed studies are needed to draw clear conclusions regarding the effect of robotassisted therapy that use end-effector-type devices on improvement of the hand motor function of patients in both the subacute and chronic stages of stroke.

\section{Exoskeleton-type robot devices}

Four randomized controlled trials of robot-assisted therapy with exoskeleton devices for improvement of upper limb motor function after stroke were selected for review (Table 2). ${ }^{46-49}$ All 4 trials were performed in patients in the chronic stage of stroke. Among them, one study reported a significantly better effect on spasticity in the robot-assisted therapy group than in the conventional therapy group. ${ }^{46}$ In contrast, $\mathrm{ADL}$ function improved more markedly in the conventional therapy group that received the same amount of treatment. The other three reports demonstrated no significant difference between robot-assisted therapy with exoskeleton devices and conventional therapies. ${ }^{47-49}$ In ad- dition, there was no randomized controlled trial that investigated robot-assisted therapy with exoskeleton devices in patients with subacute stroke. Therefore, at this time there is insufficient evidence to draw a definite conclusion regarding the effect of robot-assisted therapy that uses exoskeleton devices on upper limb function in patients with stroke.

Two randomized controlled trials that examined robot-assisted therapy with exoskeleton devices for improving the hand motor function of patients with stroke were selected (Table 3)..$^{50,51}$ Both studies showed similar or better results on hand motor function in comparison with conventional therapy. However, neither trial recruited patients in the subacute stage of stroke or assessed the effect of robot-assisted therapy on ADL function. In summary, robot-assisted therapy that uses exoskeleton devices may provide similar or additional benefits for hand motor function in comparison with conventional therapy in patients with chronic stroke, but there is insufficient evidence regarding the effect of robot-assisted therapy with exoskeleton devices on the hand motor function of patients in the subacute stage of stroke.

\section{Conclusions}

Numerous recent studies have heralded the introduction of robotic devices into the field of stroke rehabilitation. Many reports have described the efficacy of robot-assisted therapy for improving motor and ambulatory function in patients with stroke. However, both ethical and methodological constraints hinder the design of double-blind randomized controlled studies of robot-assisted therapy in patients with stroke. Furthermore, there are only a few well-organized comprehensive reviews of robot-assisted therapy. ${ }^{13,42,52,53}$ Meta-analysis of robotassisted therapy is very difficult because of the heterogeneity of the robotic devices and the participants' characteristics as well as the diversity of the study designs in the literature. Therefore, it is important to consider expert opinion as well as research data in order to draw the best conclusions. In this review, we 
made an effort to analyze the effects of different types of robotic devices on upper limb and hand motor function as well as gait function. In summary, the role of robot-assisted therapy in stroke rehabilitation is currently an adjunct to rather than a replacement for conventional rehabilitation therapy. Well-designed studies with large numbers of participants that demonstrate superior efficacy for motor recovery will be necessary to establish robot-assisted therapy as an integral part of stroke rehabilitation. Analysis of the economic impact as well as the functional benefits of robot-assisted therapy is also needed. Robot-assisted therapy for stroke rehabilitation is in a dynamic phase of development and has achieved remarkable advances. Ongoping improvement of the robotic technology may enhance the efficacy and reduce the cost of such devices. Such advances will elevate robot-assisted therapy to a standard therapeutic modality in stroke rehabilitation.

\section{References}

1. Langhorne P, Bernhardt J, Kwakkel G. Stroke rehabilitation. Lancet 2011;377:1693-1702.

2. Hong KS, Bang OY, Kang DW, Yu KH, Bae HJ, Lee JS, et al. Stroke Statistics in Korea: Part I. Epidemiology and Risk Factors: A Report from the Korean Stroke Society and Clinical Research Center for Stroke.J Stroke 2013;15:2-20.

3. Barker-Collo S, Feigin VL, Parag V, Lawes CM, Senior H. Auckland Stroke Outcomes Study. Part 2: Cognition and functional outcomes 5 years poststroke. Neurology 2010;75:16081616.

4. Rigby H, Gubitz G, Phillips S. A systematic review of caregiver burden following stroke. Int J Stroke 2009;4:285-292.

5. Pekna M, Pekny M, Nilsson M. Modulation of neural plasticity as a basis for stroke rehabilitation. Stroke 2012;43:2819-2828.

6. European Stroke Organisation Executive C, Committee ESOW. Guidelines for management of ischaemic stroke and transient ischaemic attack 2008. Cerebrovasc Dis 2008;25:457-507.

7. Kwakkel G, Wagenaar RC, Twisk JW, Lankhorst GJ, Koetsier JC. Intensity of leg and arm training after primary middle-cerebral-artery stroke: a randomised trial. Lancet 1999;354:191196.

8. Esquenazi A, Packel A. Robotic-assisted gait training and restoration. Am J Phys Med Rehabil 2012;91:S217-227; quiz S228231.

9. Pignolo L. Robotics in neuro-rehabilitation. J Rehabil Med 2009;41:955-960.

10. Sivan M, O’Connor RJ, Makower S, Levesley M, Bhakta B. Systematic review of outcome measures used in the evaluation of robot-assisted upper limb exercise in stroke. J Rehabil Med
2011;43:181-189.

11. Stein J. Robotics in rehabilitation: technology as destiny. Am J Phys Med Rehabil 2012;91:S199-203.

12. Lum PS, Godfrey SB, Brokaw EB, Holley RJ, Nichols D. Robotic approaches for rehabilitation of hand function after stroke. Am J Phys Med Rehabil 2012;91:S242-254.

13. Mehrholz J, Pohl M. Electromechanical-assisted gait training after stroke: a systematic review comparing end-effector and exoskeleton devices. J Rehabil Med 2012;44:193-199.

14. Dias D, Lains J, Pereira A, Nunes R, Caldas J, Amaral C, et al. Can we improve gait skills in chronic hemiplegics? A randomised control trial with gait trainer. Eura Medicophys 2007; 43:499-504.

15. Morone G, Bragoni M, Iosa M, De Angelis D, Venturiero V, Coiro $\mathrm{P}$, et al. Who may benefit from robotic-assisted gait training? A randomized clinical trial in patients with subacute stroke. Neurorehabil Neural Repair 2011;25:636-644.

16. Peurala SH, Airaksinen O, Huuskonen P, Jakala P, Juhakoski M, Sandell K, et al. Effects of intensive therapy using gait trainer or floor walking exercises early after stroke. J Rehabil Med 2009; 41:166-173.

17. Peurala SH, Tarkka IM, Pitkanen K, Sivenius J. The effectiveness of body weight-supported gait training and floor walking in patients with chronic stroke. Arch Phys Med Rehabil 2005; 86:1557-1564.

18. Pohl M, Werner C, Holzgraefe M, Kroczek G, Mehrholz J, Wingendorf I, et al. Repetitive locomotor training and physiotherapy improve walking and basic activities of daily living after stroke: a single-blind, randomized multicentre trial (DEutsche GAngtrainerStudie, DEGAS). Clin Rehabil 2007;21:17-27.

19. Tong RK, Ng MF, Li LS. Effectiveness of gait training using an electromechanical gait trainer, with and without functional electric stimulation, in subacute stroke: a randomized controlled trial. Arch Phys Med Rehabil 2006;87:1298-1304.

20. Werner C, Von Frankenberg S, Treig T, Konrad M, Hesse S. Treadmill training with partial body weight support and an electromechanical gait trainer for restoration of gait in subacute stroke patients: a randomized crossover study. Stroke 2002;33: 2895-2901.

21. Chang WH, Kim MS, Huh JP, Lee PK, Kim YH. Effects of robot-assisted gait training on cardiopulmonary fitness in subacute stroke patients: a randomized controlled study. Neurorehabil Neural Repair 2012;26:318-324.

22. Hidler J, Nichols D, Pelliccio M, Brady K, Campbell DD, Kahn $\mathrm{JH}$, et al. Multicenter randomized clinical trial evaluating the effectiveness of the Lokomat in subacute stroke. Neurorehabil Neural Repair 2009;23:5-13.

23. Hornby TG, Campbell DD, Kahn JH, Demott T, Moore JL, 
Roth HR. Enhanced gait-related improvements after therapistversus robotic-assisted locomotor training in subjects with chronic stroke: a randomized controlled study. Stroke 2008;39: 1786-1792.

24. Husemann B, Muller F, Krewer C, Heller S, Koenig E. Effects of locomotion training with assistance of a robot-driven gait orthosis in hemiparetic patients after stroke: a randomized controlled pilot study. Stroke 2007;38:349-354.

25. Jung KH, Ha HG, Shin HJ, Ohn SH, Sung DH, Lee PKW, et al. Effects of Robot-assisted Gait Therapy on Locomotor Recovery in Stroke Patients. J Korean Acad Rehabil Med 2008;32: 258-266.

26. Mayr A, Kofler M, Quirbach E, Matzak H, Frohlich K, Saltuari L. Prospective, blinded, randomized crossover study of gait rehabilitation in stroke patients using the Lokomat gait orthosis. Neurorehabil Neural Repair 2007;21:307-314.

27. Westlake KP, Patten C. Pilot study of Lokomat versus manualassisted treadmill training for locomotor recovery post-stroke. JNeuroeng Rehabil 2009;6:18.

28. Schwartz I, Sajin A, Fisher I, Neeb M, Shochina M, Katz-Leurer $\mathrm{M}$, et al. The effectiveness of locomotor therapy using robotic-assisted gait training in subacute stroke patients: a randomized controlled trial. PM R 2009;1:516-523.

29. Burgar CG, Lum PS, Scremin AM, Garber SL, Van der Loos HF, Kenney D, et al. Robot-assisted upper-limb therapy in acute rehabilitation setting following stroke: Department of Veterans Affairs multisite clinical trial. J Rehabil Res Dev 2011; 48:445-458.

30. Conroy SS, Whitall J, Dipietro L, Jones-Lush LM, Zhan M, Finley MA, et al. Effect of gravity on robot-assisted motor training after chronic stroke: a randomized trial. Arch Phys Med Rehabil 2011;92:1754-1761.

31. Daly JJ, Hogan N, Perepezko EM, Krebs HI, Rogers JM, Goyal $\mathrm{KS}$, et al. Response to upper-limb robotics and functional neuromuscular stimulation following stroke. J Rehabil Res Dev 2005;42:723-736.

32. Fasoli SE, Krebs HI, Ferraro M, Hogan N, Volpe BT. Does shorter rehabilitation limit potential recovery poststroke? $\mathrm{Neu}$ rorehabil Neural Repair 2004;18:88-94.

33. Hesse S, Werner C, Pohl M, Rueckriem S, Mehrholz J, Lingnau ML. Computerized arm training improves the motor control of the severely affected arm after stroke: a single-blinded randomized trial in two centers. Stroke 2005;36:1960-1966.

34. Hsieh YW, Wu CY, Lin KC, Yao G, Wu KY, Chang YJ. Doseresponse relationship of robot-assisted stroke motor rehabilitation: the impact of initial motor status. Stroke 2012;43:27292734.

35. Liao WW, Wu CY, Hsieh YW, Lin KC, Chang WY. Effects of robot-assisted upper limb rehabilitation on daily function and real-world arm activity in patients with chronic stroke: a randomized controlled trial. Clin Rehabil 2012;26:111-120.

36. Lo AC, Guarino PD, Richards LG, Haselkorn JK, Wittenberg GF, Federman DG, et al. Robot-assisted therapy for long-term upper-limb impairment after stroke. N Engl J Med 2010;362: 1772-1783.

37. Lum PS, Burgar CG, Shor PC, Majmundar M, Van der Loos M. Robot-assisted movement training compared with conventional therapy techniques for the rehabilitation of upper-limb motor function after stroke. Arch Phys Med Rehabil 2002;83: 952-959.

38. Lum PS, Burgar CG, Van der Loos M, Shor PC, Majmundar M, Yap R. MIME robotic device for upper-limb neurorehabilitation in subacute stroke subjects: A follow-up study. J Rehabil Res Dev 2006;43:631-642.

39. Masiero S, Armani M, Rosati G. Upper-limb robot-assisted therapy in rehabilitation of acute stroke patients: focused review and results of new randomized controlled trial. J Rehabil Res Dev 2011;48:355-366.

40. Masiero S, Celia A, Rosati G, Armani M. Robotic-assisted rehabilitation of the upper limb after acute stroke. Arch Phys Med Rehabil 2007;88:142-149.

41. Wu CY, Yang CL, Chuang LL, Lin KC, Chen HC, Chen MD, et al. Effect of therapist-based versus robot-assisted bilateral arm training on motor control, functional performance, and quality of life after chronic stroke: a clinical trial. Phys Ther 2012;92: 1006-1016.

42. Mehrholz J, Hadrich A, Platz T, Kugler J, Pohl M. Electromechanical and robot-assisted arm training for improving generic activities of daily living, arm function, and arm muscle strength after stroke. Cochrane Database Syst Rev 2012;6:CD006876.

43. Connelly L, Jia Y, Toro ML, Stoykov ME, Kenyon RV, Kamper DG. A pneumatic glove and immersive virtual reality environment for hand rehabilitative training after stroke. IEEE Trans Neural Syst Rehabil Eng 2010;18:551-559.

44. Fischer HC, Stubblefield K, Kline T, Luo X, Kenyon RV, Kamper DG. Hand rehabilitation following stroke: a pilot study of assisted finger extension training in a virtual environment. Top Stroke Rehabil 2007; 14:1-12.

45. Hwang CH, Seong JW, Son DS. Individual finger synchronized robot-assisted hand rehabilitation in subacute to chronic stroke: a prospective randomized clinical trial of efficacy. Clin Rehabil 2012;26:696-704.

46. Fazekas G, Horvath M, Troznai T, Toth A. Robot-mediated upper limb physiotherapy for patients with spastic hemiparesis: a preliminary study. J Rehabil Med 2007;39:580-582.

47. Kahn LE, Zygman ML, Rymer WZ, Reinkensmeyer DJ. Ro- 
bot-assisted reaching exercise promotes arm movement recovery in chronic hemiparetic stroke: a randomized controlled pilot study. J Neuroeng Rehabil 2006;3:12.

48. Mayr A, Kofler M, Saltuari L. [ARMOR: an electromechanical robot for upper limb training following stroke. A prospective randomised controlled pilot study]. Handchir Mikrochir Plast Chir 2008;40:66-73.

49. Housman SJ, Scott KM, Reinkensmeyer DJ. A randomized controlled trial of gravity-supported, computer-enhanced arm exercise for individuals with severe hemiparesis. Neurorehabil Neural Repair 2009;23:505-514.

50. Kutner NG, Zhang R, Butler AJ, Wolf SL, Alberts JL. Qualityof-life change associated with robotic-assisted therapy to im- prove hand motor function in patients with subacute stroke: a randomized clinical trial. Phys Ther 2010;90:493-504.

51. Takahashi CD, Der-Yeghiaian L, Le V, Motiwala RR, Cramer SC. Robot-based hand motor therapy after stroke. Brain 2008; 131:425-437.

52. Mehrholz J, Werner C, Kugler J, Pohl M. Electromechanical-assisted training for walking after stroke. Cochrane Database Syst Rev 2007:CD006185.

53. Norouzi-Gheidari N, Archambault PS, Fung J. Effects of robotassisted therapy on stroke rehabilitation in upper limbs: systematic review and meta-analysis of the literature.J Rehabil Res Dev 2012;49:479-496. 